\title{
Forest Health: An Integrated Perspective
}

John D. Castello and Stephen A. Teale. 2011. ISBN 978-0-521-74741-7 Cambridge University Press, New York. \$ US 49.00 + shipping.Contact:publicity@cambridge.org

A $s$ foresters we believe that we know what a healthy forest looks like but when asked to quantify our definition quickly realize that our definition may not take into account all of the complexities that constitute a healthy forest. Forest Health: An Integrated Perspective edited by John D. Castello and Stephen A. Teale examines forest health from an ecological point of view and gives much food for thought as to the factors that need to be considered when determining what a healthy forest is all about.

The book challenges the traditional view of what forest managers believe constitutes a healthy forest. Chapters 1 and 2: The past as a key to the future: $a$ new perspective on forest health and Mortality: the essence of a healthy forest, establish the framework for the rest of the book. The chapters that follow provide a thorough examination of the many factors that impact forest health. Baseline mortality, which is defined as the number of stems of a given size class that must die in order for a population to maintain a stable size structure, is a concept that is promulgated throughout the book. Foresters are taught to manage the forest in a way that trees are harvested before mortality occurs. Castello and Teale see mortality as an integral component of forest health. Many of the arguments and examples are evaluated using baseline mortality as a central theme.

Resource managers often equate threats to the forest such as insects, diseases, fires, climate, and pollution as factors deleterious to the health of the forest. The determination of what is considered harmful is usually the result of human values placed on the forest by resource managers. For example, the term "forest insect" is usually associated with insects that are considered to be harmful to the forest. However, only a small proportion of forest insects actually cause damage to trees. The book views forest health in a much broader scope and examines forest insects as well as many other biotic and abiotic factors and discusses the role these play in determining what constitutes a healthy forest.

Chapter 5: Alien invasions: the effects of introduced species on forest structure, is dedicated entirely to invasive species and the significant threat they pose to forest ecosystems. Shifting patterns of trade, globalization of economies, and climate change have ensured that even the most remote and pristine forests are not immune to this threat. Chestnut blight resulted in the elimination of American chestnut as a canopy-dominant species in eastern North America. The recently invasive emerald ash borer has the potential to cause a similar impact to ash resources on the North American continent. Many other examples are cited that illustrate the risk associated with these alien invasive species and the significant changes to ecosystems that have resulted from their introduction.

Chapter 8: Timber harvesting, silviculture, and forest management: an axe does not a forester make, looks at the evolution of forest management and how silviculture and forest management focus on managing tree communities to create forests that satisfy societal needs. The authors compare the four-phase model of forestry described by Kimmins in Forest Ecology: A Foundation for sustainable Development, to Marlow's Hierarchy of Needs. When people use the forest for basic needs of food and shelter, concerns for forest health are very low. It is only with the removal of people from a direct life-needs connection to forests that the later phases of development can occur. In many places in the world the use of forestry is still primary, where trees and forests are still necessary to meet basic life needs. Conversely, forestry in many other places are fully in Kimmins' fourth phase where ecological, social and economic

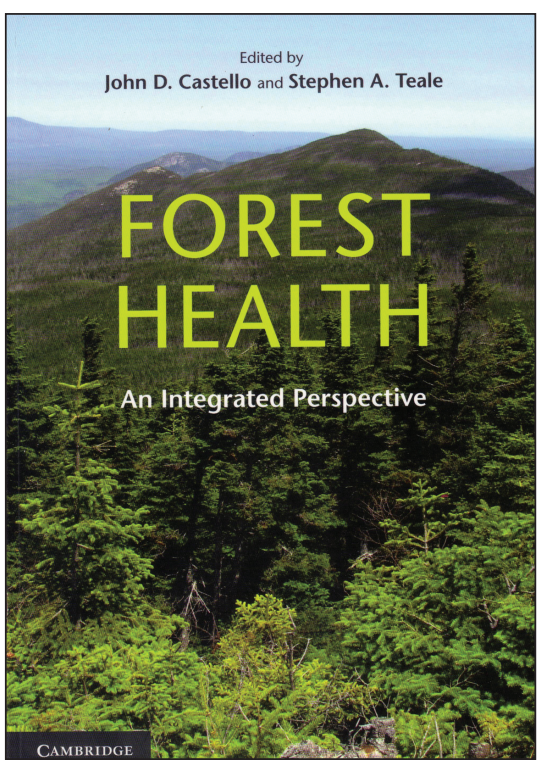

elements of management are also considered. The expectations placed on how these forests are managed and the importance that is given to the values a healthy forest is very different.

Forest Health: An Integrated Perspective is foremost an ecology textbook as most of the arguments are explained using ecological principles. Case studies, citing examples from around the world, are used to explain in ecological terms how various events have impacted forest health. Many jurisdictions are shifting their focus on forest management to reflect more of an ecosystem-based approach that better represents societal values. We believe that this book views forest health in a way that is consistent with this new approach and provides an insightful new perspective on forest health and is an excellent book for students, forestry practitioners and policy advisors.

Reviewed by a member of the CIF/IFC Maritime Section 